\title{
Tres déCADAs DE CONSERVACIÓN DEL PATRIMONIO ARQUEOLÓGICO EN ESPAÑA (I978-2008)
}

\author{
Ascensión Hernández Martínez
}

\footnotetext{
69 Sobre esse tema pueden consultarse las siguientes obras: QUEROL, M ${ }^{\mathrm{a}}$ Ángeles; MARTÍNEZ DÍAZ, Belén. La gestión del patrimonio arqueológico en España. Madrid: Alianza, 1996; RODRÍGUEZ TEMIÑO, Ignacio: Arqueología urbana en España. Barcelona: Ariel, 2004

70 El País, Madri, 27 julio 2006.
}

\section{INTRODUCCIÓN}

Si la evolución de los criterios de restauración en España a lo largo de las tres últimas décadas, en un nuevo período que entra plenamente dentro de la historia reciente de España como es la instauración de la democracia, se puede reconstruir analizando las intervenciones realizadas en diversos monumentos, el patrimonio arqueológico sin duda alguna nos sirve perfectamente para estudiar e individualizar las diferentes tendencias que se han producido a lo largo de este período.

Desde la actitud claramente intervencionista y reconstructora, con inserción de nueva arquitectura en el teatro romano de Sagunto, que corresponde a los primeros momentos de la democracia, cuando encontramos una actitud de virulenta defensa de la modernidad como reacción a la restauración historicista practicada bajo el franquismo (una tendencia que, como veremos, ha causado muchos problemas posteriores), hasta la voluntad de discreción que evidencia la restauración de la muralla nazarí de Granada, un ejemplo de "recomposición de una laguna arquitectónica", cuya calidad ha sido reconocida con la concesión de premios nacionales e internacionales.

Debemos partir de una reflexión previa. El patrimonio arqueológico español había sufrido mucho a lo largo de los siglos 19 y 20, puesto que excepto en los grandes yacimientos, romanos o musulmanes, como Mérida o Medina-Azhara, quedaba mucho por estudiar y conservar, por ello la conservación del ingente patrimonio arqueológico español ha sido uno de los retos fundamentales a abordar desde la Administración Pública, una vez instaurada la democracia ${ }^{69}$. Objeto de expolio durante gran parte de los siglos 19 y 20, una de las tareas prioritarias del Ministerio de Cultura, y con posterioridad de las Comunidades Autónomas tras la transferencia de la gestión en materia de patrimonio a mediados de los años ochenta (Ley de patrimonio histórico español, 1985), ha sido tanto la puesta en marcha de extensas campañas arqueológicas para completar un conocimiento difuso e irregular del mismo, como la conservación, restauración y musealización de los numerosos restos conservados. Esta tarea ha encontrado grandes obstáculos, en particular cuando se trata de restos conservados en el interior de los centros históricos de las ciudades españolas, sujetos por tanto a fuertes procesos de transformación urbana a menudo condicionados por la especulación inmobiliaria como pone de manifiesto las tensiones sufridas en el seno de la Junta de Castilla y León y del Ayuntamiento de Toledo para conservar los importantísimos restos arqueológicos de época visigoda de la capital toledana ${ }^{70}$. Su tratamiento y puesta en valor tampoco ha escapado a la creciente teatralización y conversión en espectáculo a la que se ve sometido cada vez más el patrimonio cultural, obligándonos a cuestionar muchas actuaciones que persiguen más la captación de público a costa de lo que sea (los mismos restos), que la verdadera conservación (y conocimiento) de los mismos. 
Por último, es preciso señalar que la publicación en junio de 1985 de la Ley de patrimonio histórico español marcó un hito al establecer en su artículo 39.2 los criterios de intervención a seguir en la restauración del patrimonio monumental español.

Las actuaciones irán encaminadas a la conservación, consolidación y rehabilitación, y evitarán los intentos de reconstrucción, salvo cuando se utilicen partes originales de los mismos y pueda probarse su autenticidad. Si se añadiesen materiales, o partes indispensables para su estabilidad o mantenimientos, las adiciones deberán ser reconocibles y evitar confusiones miméticas.

71 POL, Francisco. La recuperación de los centros históricos en España. In: Arquitectura y Urbanismo en las ciudades históricas. I Curso sobre proyectos urbanos e intervenciones arquitectónicas en la recuperación de las ciudades históricas. Cuenca: Universidad Internacional Menéndez Pelayo, 1986. Madri: Ministerio de Obras Públicas y Transportes, 1988 , p. 26-47.

\section{Casos de estudio}

Son muchas las intervenciones de interés, entre ellas podemos destacar una selección realizada por diversas circunstancias. Presentadas por orden cronológico, en primer lugar debemos reseñar la recuperación de La Muralla Tardorromana de Gijón descubierta en 1982 y reconstruida en 1989 en ladrillo a partir del basamento en piedra sillar encontrado en unas excavaciones, proyecto que se completó con la creación del parque arqueológico de Campo Valdés (1990), musealizando subterráneamente las termas de la ciudad romana, y la reconstrucción de una torre vigía, donde se alojaba el concejo municipal y la cárcel hasta 1911 cuando fue demolida, que se convierte ahora en un centro de interpretación de la historia de la ciudad. Este proyecto, que formaba parte del Plan especial de protección del Centro Histórico de Gijón dirigido por el arquitecto Francisco Pol71 y José Luis Martín, devolvía a esta localidad asturiana la imagen de una ciudad romana, completando para la memoria histórica colectiva una época hasta entonces desconocida de su pasado. Además el conjunto de actuaciones desarrolladas formaba parte de un plan estratégico de

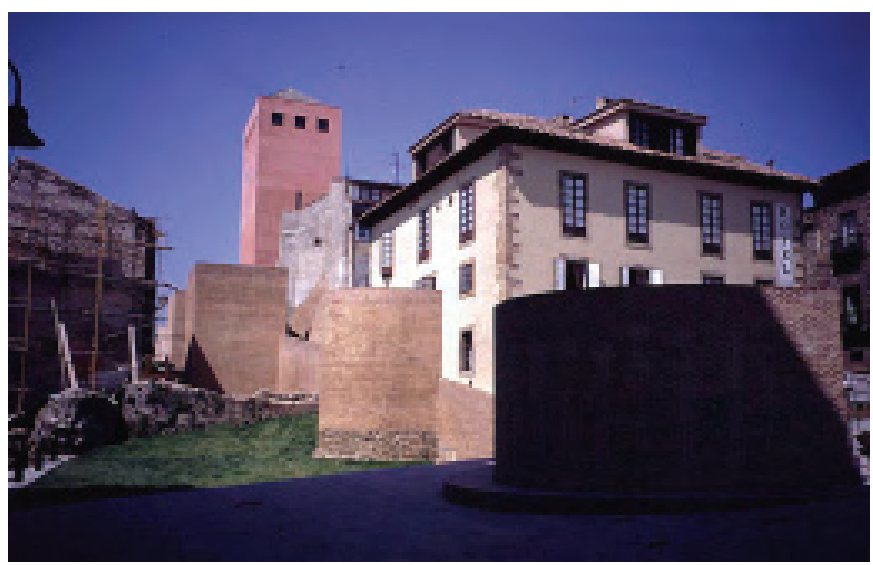

Figura 1: Gijón. Vista general de la reconstrucción de la muralla Foto: Autora

Figura 2: Gijón. Detalle de la torre vigía reconstruida Foto: Autora

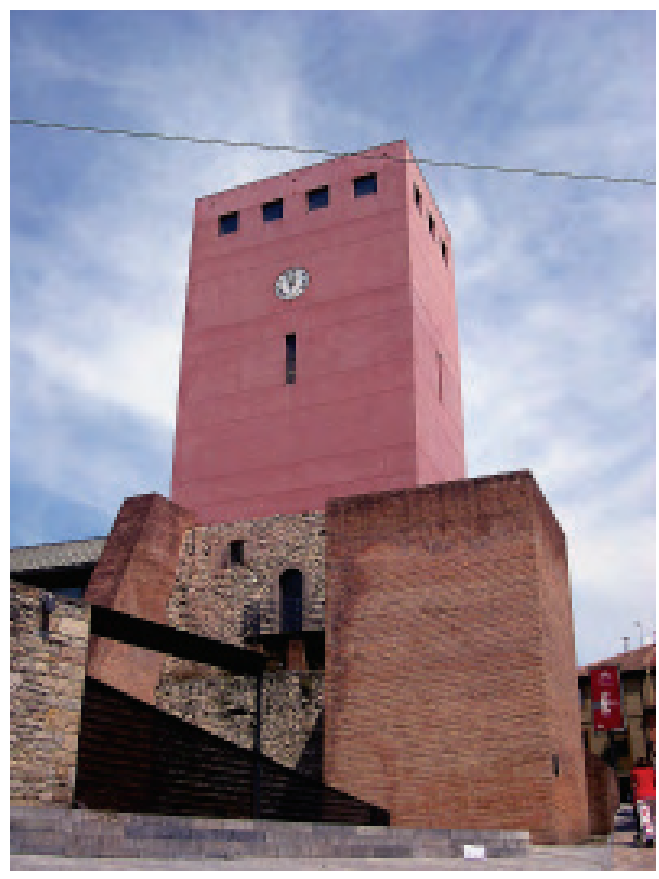


72 GRASSI, Giorgio. Sagunto: restauro e riabilitazione del teatro romano. In: PIERINI, Simona (Org.). Giorgio Grassi. Progetti per la città antica. Milão: Motta, 1995 recuperación del centro urbano de esta villa marinera de 600.000 habitantes, terriblemente deteriorado, con graves problemas estructurales (mal estado general de las viviendas y construcciones, una población débil, envejecida o con colectivos mal integrados, desocupación laboral y marginalidad social, abandono y desinterés del resto de la ciudad hacia esta zona). En este sentido, el caso de Gijón es modélico respecto a la política de recuperación urbana de los centros históricos españoles, que se encontraban en una situación de crisis a finales de la década de los setenta del siglo pasado, desarrollada en nuestro país en la década de los 80 con la llegada de los primeros ayuntamientos democráticos.

La intervención en los restos arqueológicos romanos de Gijón, situados en la ladera de una península cuya parte norte, al mar, es un escarpe de gran valor paisajístico, va más allá de la estricta conservación, dado que se ha reconstruido una parte importante de su volumen (no en su totalidad porque se desconoce su altura real), reproduciendo su perfil con torreones circulares, pero cambiando el material para no confundirlo con los restos originales. Desde el punto de vista de los criterios de conservación no era una actuación estrictamente necesaria y, probablemente, de haberse propuesto años después, una vez promulgada la Ley de patrimonio histórico español de 1985, donde se establece que el objetivo de una restauración debe ser la estricta conservación de los restos o del inmueble, no se habría llevado a cabo. Quizás debamos buscar la justificación de este proyecto en el contexto histórico en que se sitúa: los primeros años de la democracia española, cuando se pusieron en práctica actuaciones en materia de patrimonio que querían hacer visible la voluntad de cambio político y cultural de la nueva administración pública y la creciente concienciación social hacia el patrimonio cultural, abandonado y destruido durante décadas bajo el franquismo. Por esta razón, la muralla de Gijón es un ejemplo de la importancia decisiva que cobra el patrimonio cultural en la política urbanística española en la década de los ochenta y la reconstrucción de sus torres el símbolo manifiesto de la voluntad y el deseo de recuperar el centro histórico. Además, esta intervención se completaba con otras actuaciones igualmente interesantes que seguían unos principios claros asumidos en las intervenciones en otros centros históricos españoles: la recualificación de los espacios públicos, la inserción de edificios de mayor impacto con un uso público o cultural, una cierta permisividad de las restauraciones admitiendo reconstrucciones, sustituciones y adiciones con el objetivo de recuperar edificios históricos que dinamizasen zonas degradadas y el desarrollo de instrumentos efectivos de gestión y promoción para la promoción de políticas municipales de apoyo a la rehabilitación privada de viviendas.

En Gijón estos principios se materializaron en la introducción de nuevos usos en edificios históricos de la zona (rehabilitación del Palacio de Revillagigedo del siglo 18, convertido en centro de exposiciones y otros eventos culturales, de edificios históricos para uso cultural, e instalación de la nueva sede del Colegio Oficial de Arquitectos de Asturias en una vivienda según proyecto del estudio Ruiz-Larrea Arquitectos); asimismo, se insertaron piezas de arte público contemporáneo (Elogio al horizonte, de Eduardo Chillida) en un parque situado en la parte más alta del cerro, como un nuevo elemento de atracción para ciudadanos y turistas, también se apoyó la rehabilitación de viviendas privadas y, finalmente, se recuperó el puerto marinero situado a los pies del cerro, convirtiéndolo en un moderno puerto deportivo.

Pocos años después, en 1993, se concluía la intervención de Giorgio Grassi ${ }^{72}$ y Manuel Portaceli en el Teatro Romano de Sagunto, Valencia. 


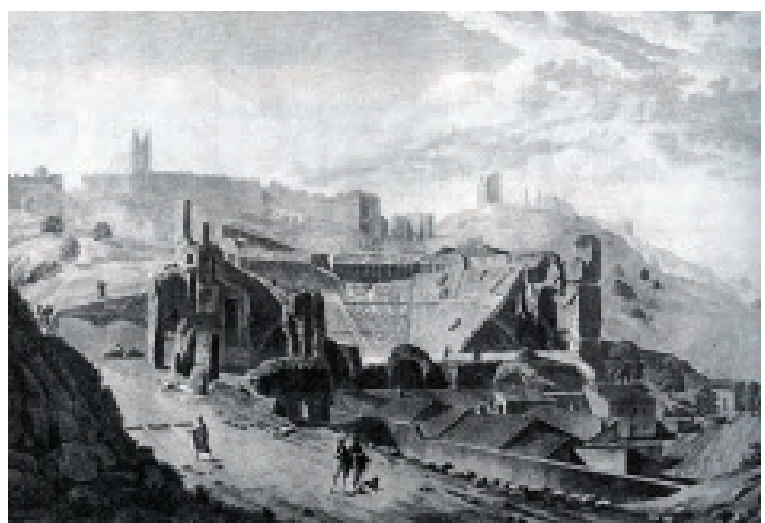

Figura 3: Teatro romano de Sagunto. Grabado original de 1842, por Lavallé Geroult y Lacroix

Fuente: Procedente de L'Univers Pittoresque. Colección Particular

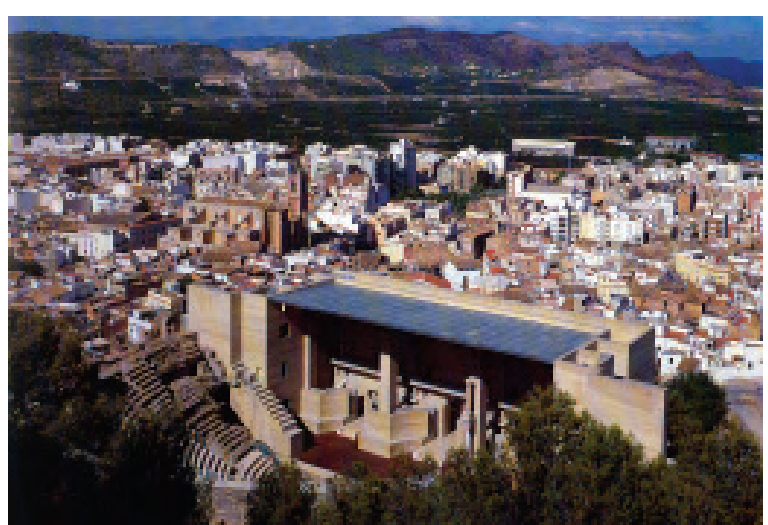

Figura 4: Teatro romano de Sagunto. Estado actual Fuente: Imagen publicada en la revista $R \& R$. Restauración y Rehabilitación, n. 79, septiembre 2003

\section{4}

73 Reconstrucción monumental. Restauración y rehabilitación del teatro romano de Sagunto. Interpretación de la Ley 16/ 1985 de 25 de junio, de Patrimonio Histórico Español, Actualidad Jurídica Aranzadi, n. 458, p. 12-13, 26 de octubre de 2000.

74 Sobre la polémica de Sagunto consultese: ALMAGRO, Antonio. Arde Sagunto. La polémica restauración del Teatro Romano, Arquitectura Viva, Madrid, n. 32, p. 66-69, 1993; NAVASCUÉS PALACIO, Pedro. Presente del pasado. La condición histórica de la arquitectura, Arquitectura Viva, Madri, n. 33, p. 22-25, 1993; CAPITEL, Antón. La transformación del Teatro Romano de Sagunto: una arquitectura declarada culpable, Arquitectura, n. 328, p. 100-101, 2002; Cuatro visiones sobre el teatro romano de Sagunto, $R \& R$. Restauración y Rehabilitación, Valencia, n. 79, p. 29-45, septiembre 2003, recogiendo la opinión de Emilio Giménez, Antón Capitel, Javier Rivera Blanco y Alberto Ustarroz; ESTEBAN CHAPAPRÍA, Julián. Si un tiempo fuertes,
El proyecto se había puesto en marcha en 1984, mediante el encargo directo a los arquitectos realizado por el entonces Director General de Patrimonio Artístico de la Consejería de Cultura de la Generalitat de Valencia, Tomás Llorens, generando ya controversia y oposición al conocerse al año siguiente. Realizada la obra, con la aprobación de todas las autoridades pertinentes, mucho se ha escrito dentro y fuera de nuestro país sobre el tema, haciendo de éste sin duda el caso más polémico y difundido de la restauración monumental en España en este período. Lo lamentable es que, con denuncias de por medio, esta historia ha concluido con dos sentencias judiciales del Tribunal Superior de Justicia primero y del Tribunal Supremo después $(2000)^{73}$, que decretan el derribo de la intervención al considerarla excesiva, por contravenir el artículo 39.2 de la Ley de patrimonio histórico español. Antes de esta intervención, el teatro romano de Sagunto era una ruina consolidada como tal desde hacía siglos, la escena se había perdido completamente y de las gradas de la cávea quedaban pocos restos que habían sido consolidados en intervenciones precedentes. Sobre estos restos, desde los que se tenía una vista completa de la ciudad, la propuesta realizada en 1983 por Grassi y Portaceli consistía en construir un teatro romano de nueva planta, una reconstrucción hipotética inspirada en las ruinas conservadas y en otros teatros romanos, donde se levantaba una caja escénica de grandes dimensiones, colocándose gradas de mármol sobre los restos originales, una actuación de dudosa reversibilidad.

Las opiniones sobre el nuevo teatro, puesto que así puede calificarse el volumen añadido a la construcción histórica, son dispares y encontradas: desde el arquitecto Antón Capitel que lo considera un "valiente ejercicio de analogía", al arquitecto Antonio Almagro o al historiador Pedro Navascués Palacio quienes lo critican por considerar la intervención innecesaria y dañina para el monumento ${ }^{74}$. En nuestra opinión, se trata de un ejemplo más de una actitud generalizada en la posmodernidad, en la que la ruina se considera una excusa para crear una obra nueva, una actitud inaceptable desde el punto de vista de respeto al valor histórico, artístico y cultural del monumento, más próxima a la práctica del collage o del reciclaje tan frecuente hoy en el mundo de las artes plásticas, pero insostenible en el ámbito de la restauración monumental. En cualquier caso consideramos, siguiendo otras opiniones expresadas ya al respecto (entre otras del 
ya desmoronados. Notas sobre el Teatro Romano de Sagunto. In: 2a BIENAL de la Restauración Monumental (Actas), Vitoria, 2004, p. 91-99.

75 "El Consell busca ahora consenso para el teatro romano de Sagunto", El País, edición comunidad valenciana, 4 enero 2008, p. 4

76 NAVASCUÉS PALACIO, Pedro. El teatro romano de Sagunto: ayer, hoy y mañana. Carta de un escéptico a don Antonio Ponz sobre el teatro de Sagunto. In: DEL AYER para el mañana. Medidas de protección del patrimonio, actas del Simposio Internacional celebrado en noviembre 2003. Valladolid: Fundación del Patrimonio Histórico de Castilla y León, 2004, p. 414

77 MACARRÓN, Ana. Restauración de los teatros romanos de Mérida y Sagunto. In: CONSERVACIÓN del patrimonio cultural. Criterios y normativas. Madri: Editorial Síntesis, 2008, p. 196-198.

78 AIMEUR, Carlos. Mil intelectuales apoyan el "lifting" del teatro romano de Sagunto, El Mundo, 31 enero 2008, p. 56.

79 GARRIDO, Lidia. Los arquitectos prevén graves daños en el teatro romano si se interviene. El País, Edición comunidad valenciana, 6 enero 2008, p. 3.

80 OLIVIERI, Davide. Una rovina è una rovina...non c'è restauro che tenga. II teatro romano di Sagunto ritornerà rudere? II mondo culturale si movilita, /I Giornale dell'architettura, Milano, n. 59, febbraio 2008, p. 12. director, Ramón González de Amezúa ${ }^{75}$, y del subdirector, Pedro Navascués Palacio, de la Real Academia de Bellas Artes de San Fernando), que a pesar de la condenatoria sentencia judicial la intervención no debería derribarse porque es irreversible y ninguna acción desrestauradora podría devolver el teatro a su situación original. Por otro lado, este controvertido episodio forma parte ya de la historia del edificio y podría quedar, en nuestra opinión, como ejemplo pedagógico de aquello que no puede admitirse de ninguna manera en la restauración de un resto arqueológico, un caso único que no se habría producido jamás en ningún otro lugar de Europa que no fuera España.

El arquitecto italiano Grassi hizo en Sagunto lo que no le hubieran permitido hacer las leyes ni la práctica restauradora en su país sobre teatros como los de Ostia o Pompeya. En otras palabras, no hay teatro clásico en todo el Mediterráneo que haya sufrido tal ultraje, ni administración cultural que haya permitido semejante actuación ${ }^{76}$, decía Pedro Navascués al respecto.

Creo que resulta clarificador citar como antecedentes históricos en la intervención de restos arqueológicos en España dos ejemplos de actuaciones bien distintas: la anastylosis del teatro romano de Mérida realizada por José Menéndez Pidal en 1917 y la consolidación estructural del propio teatro de Sagunto llevada a cabo por Jerónimo Martorell en los años treinta (1930-1935). En el primer caso, Menéndez Pidal recolocó los elementos originales existentes de la escena (una gran parte de las columnas de los dos pisos, parte de las dos cornisas y arquitrabes y frisos), desmontando una incorrecta restauración precedente para situarlos en su ubicación más exacta, como precisa certeramente Ana Macarrón ${ }^{77}$. En cuanto a las gradas, se restituyeron parcialmente con nuevos sillares realizados en piedra artificial, lo que permitió recuperar la función teatral original. En el caso de Martorell, la intervención consistió en el apeo de elementos utilizando un recurso (el sottoscuadro) también empleado en la restauración italiana, y en la ordenación de los restos para facilitar el paseo, convirtiendo la ruina en un interesante jardín arqueológico.

La situación actual en la que se encuentra el teatro es sumamente complicada. En enero de 2008 el Tribunal Supremo confirmó a la Generalitat de Valencia (la administración local) el plazo de 18 meses para ejecutar la sentencia de derribo decretada en abril de 2003. Esta ratificación ha producido una gran inquietud social en la ciudad, puesto que muchos saguntinos se oponen hoy por diversas razones, económicas y sociales (el derribo, que se cifra entre seis y nueve millones de euros, debe realizarse a costa del erario público y el teatro se usa habitualmente para eventos culturales, además de ser visitado por numerosos turistas), encendiéndose al mismo tiempo de nuevo la polémica en el medio cultural, hasta tal punto que se ha hecho público un manifiesto firmado por artistas, arquitectos e intelectuales en contra del derribo, por considerarlo "un ataque a la independencia y la libertad del mundo de la cultura"78 (es necesario precisar que entre los firmantes aparecen figuras del mundo del espectáculo que carecen de conocimiento alguno en materia de restauración del patrimonio artístico). Entre los arquitectos domina la opinión de que la actuación de Grassi y Portaceli es difícil y costosa de eliminar ${ }^{79}$, y en general abunda la sensación de que esta intervención se ha manipulado políticamente en exceso, hasta llegar a un punto sin retorno ${ }^{80}$. Por su parte la Generalitat manifiesta no saber qué hacer con este caso, por lo cual resulta impredecible preveer qué puede pasar con este monumento que, como manifiesta el historiador Pedro Navascués, Catedrático de 
81 NAVASCUÉS, 2004, op. cit.

82 Teatro romano de Caesaraugusta, In: RESTAURAR HISPANIA, Catálogo de la exposición. Madri: Ministerio de Educación y Ciencia y Ministerio de Fomento, 2002, p. 108-109.

83 Proyecto de ejecución del Museo Romano de Zaragoza, 2001. Ayuntamiento de Zaragoza. la Escuela de Arquitectura de Madrid y Subdirector de la Real Academia de Bellas Artes de San Fernando, ha perdido ya lo que de interesante y valioso tenía antes de la intervención ${ }^{81}$.

Un ejemplo completamente opuesto al anterior es el del Teatro Romano de Zaragoza ${ }^{82}$, descubierto en 1972, declarado Monumento Nacional en esa fecha, excavado y estudiado durante las décadas posteriores y, finalmente, restaurado y musealizado en 2003, según proyecto de los arquitectos Úrsula Heredia Lagunas y Ramón Velasco ${ }^{83}$, gozando en la actualidad del máximo nivel de protección legal (es un Bien de Interés Cultural).

En este caso nos encontramos con la puesta en valor de unos restos difíciles de comprender, ya que habían perdido su potencia arquitectónica puesto que del teatro original que databa de la época final del gobierno del emperador Tiberio, sólo se conservan los cimientos y parte del escenario. El teatro, construido en la primera mitad del siglo I d.C, había sido abandonado y desmontado desde mediados del siglo III d.C., perdiéndose la noción de su existencia hasta su descubrimiento a comienzos de la década de los setenta. Su configuración estructural, formada por anillos concéntricos arriostrados por muros radiales, responde al sistema del teatro Marcelo de Roma, y por sus medidas exteriores (107 metros de diámetro) se le calcula un aforo de 6.000 espectadores, por lo que era uno de los más grandes de España, confirmando la importancia de Caesaragusta (Zaragoza) como urbe en aquel período histórico. Según la opinión de los especialistas, es un magnífico exponente de la arquitectura pública y monumental romana del siglo I.

A pesar de la escasa entidad arquitectónica de los restos encontrados (al menos en comparación con otros teatros romanos españoles como los de Mérida y Sagunto), éstos tienen un gran valor histórico para la ciudad, por ello se han integrado en un modélico centro de interpretación instalado en un edificio del siglo XIX, que se levantó en tiempos junto al teatro, donde se sitúa un excelente

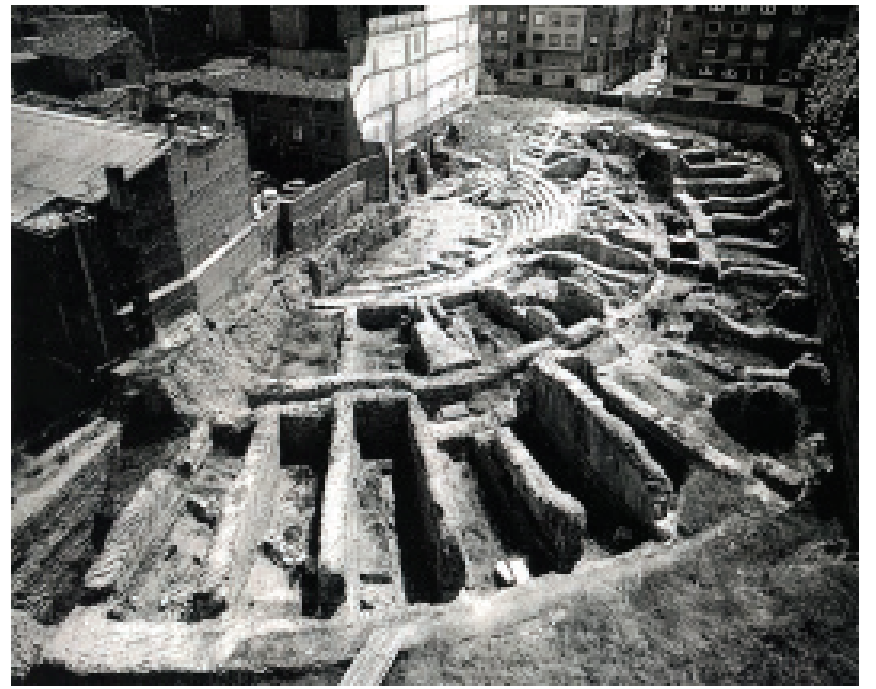

Figura 5: Descubrimiento del teatro romano de Zaragoza en 1972 Fuente: Servicio Municipal de Arqueología del Ayuntamiento de Zaragoza

Figura 6: Teatro romano de Zaragoza. Estado actual Foto: Autora

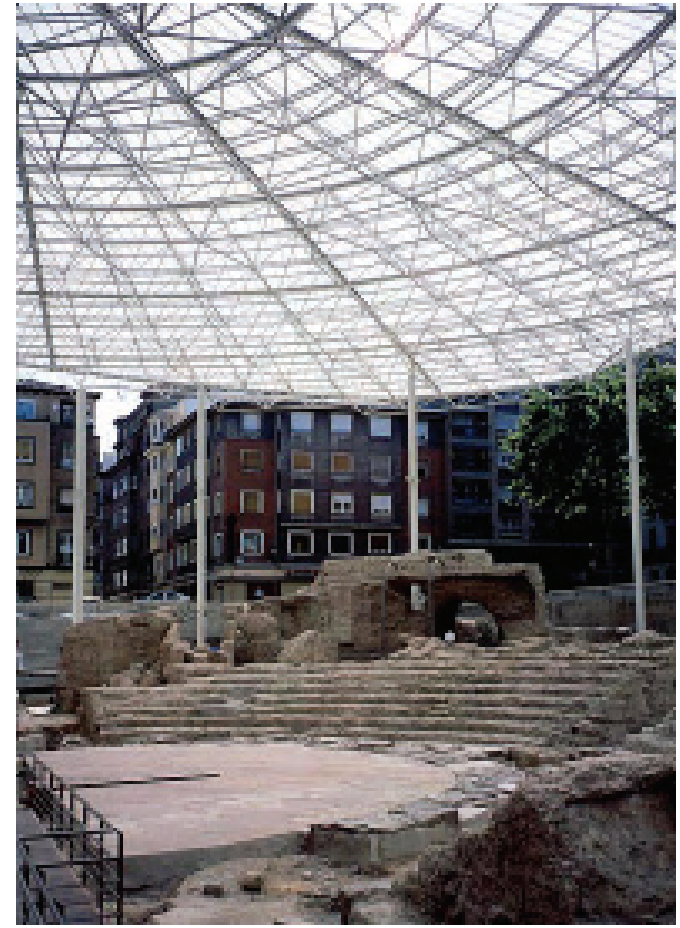


84 RUBIO, M ${ }^{a}$ José. Muralla nazarí en el Albaicín Alto de Granada. Premio de Arquitectura Piedra 2006, Piedra Natural, Madri, n. 77, año VII, septiembre 2006. museo del teatro. Éste, a su vez, forma parte de una red municipal de museos y centros de la historia y la arquitectura romana en la capital aragonesa (Museo del Foro-1995, Museo de las Termas-1999, Museo del Puerto Fluvial-2000 y tramos de la muralla romana), apoyada y reforzada con la puesta en marcha del Plan integral del Casco Histórico de Zaragoza en 1998, subrayando de esta manera la trascendencia de la romanización en la historia de Zaragoza. En este sentido, se trata de un magnífico ejemplo de conservación y difusión de restos arqueológicos integrados en un centro histórico centenario, en el que se superponen diferentes etapas desde la fundación de la ciudad en época del emperador Augusto entre los años 19 y 14 a.C. hasta la actualidad.

Desde el punto de vista de criterios de restauración, la intervención ha tenido un fuerte carácter conservador, limitándose a la limpieza, consolidación y protección de los restos encontrados que eran la estructura del teatro realizada en hormigón (opus caementicium), que se ha limpiado y consolidado con un mortero similar al original y también con una malla de fibra de vidrio; asimismo, ha sido necesario colocar dos bloques de cemento Pórtland y dos arcos de hierro para soportar partes de la estructura que estaban inestables, diferenciándolos visualmente de lo antiguo. En cuanto a los restos del suelo del escenario (orchestra) encontrados, se restituyeron en su lugar sobre una capa de fibra de vidrio de distinto color. A continuación, se insertaron pasarelas desmontables para facilitar la visita al monumento. Como novedad, se ha construido una gran cubierta traslúcida suspendida a más de 20 metros de altura que serviría para proteger los restos arqueológicos de los nocivos rayos UV, a la vez que para recomponer visualmente el volumen original de la construcción. Se trata de una malla reticular fácilmente desmontable que, de acuerdo con las recomendaciones y criterios internacionales, no se apoya en los restos sino en la grava dispuesta sobre ellos.

Una intervención igualmente interesante, pero muy distinta en origen, es la realizada por el arquitecto Antonio Jiménez Torrecillas en La Muralla Nazarí de Granada ${ }^{84}$ (2000-2006), que ha sido destacada por su calidad con la obtención de diversos premios (Premio Internacional de Arquitectura Piedra 2006, finalista

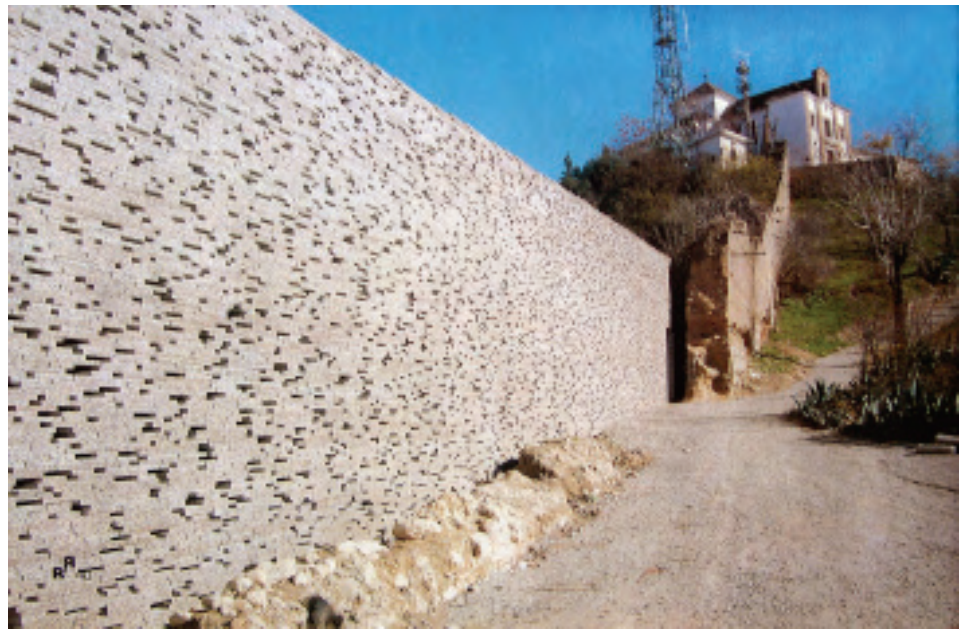

Figura 7: Vista general de la reconstrucción de la muralla nazarí de Granada Foto: Autora

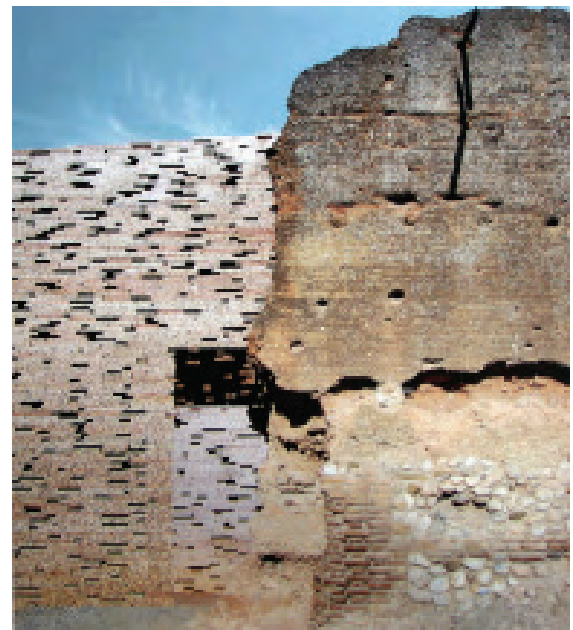

Figura 8: Detalle de la zona de contacto entre la parte reconstruida (izda) y la original en tapial (dcha) de la muralla nazarí de Granada Foto: Autora 


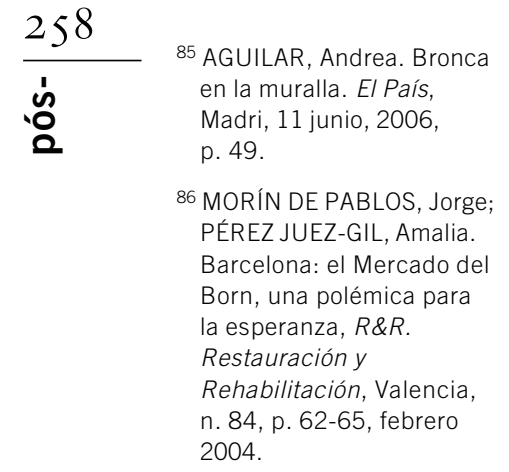

5 AGUILAR, Andrea. Bronca p. 49

MORÍN DE PABLOS, Jorge: Born, una polémica para Rehabilitación, Valencia, 2004 del IV Premio Europeo del Espacio Público Urbano 2006 y preseleccionada para el Premio Mies van der Rohe 2007).

Este monumento tenía una fractura, había perdido su continuidad lineal a causa de un terremoto producido en el siglo 19 que causó la caída de unos 40 metros de muralla. Ésta se remonta al siglo 16, cuando fue construida para delimitar el cerco administrativo de la ciudad y está situada sobre el cerro de San Miguel y la parte alta del Albaicín, frente a la Alhambra. El proyecto de intervención comprendía la restitución del tramo perdido de la muralla y la adecuación paisajística de todo el conjunto, puesto que por su interés se consideraba que debía ser preservado como un paisaje natural humanizado. La actuación, por tanto, incluyó diversos niveles: la limpieza general del conjunto, respetando los característicos campos de pitas y chumberas de la zona, la restauración de la ermita de San Miguel Alto, situada sobre el cerro, y la mejora de los accesos, respetando el empedrado original en los caminos o completándolo en las partes perdidas con un pavimento blando de tierra apisonada.

En cuanto a la muralla, se decidió su completamiento con una obra nueva para restituir su continuidad, tratándola como si fuera la reintegración de una laguna pictórica, guiándose la intervención por los criterios de reversibilidad, compatibilidad y notoriedad visual y el concepto de sólido capaz utilizado por Leopoldo Torres Balbás en el pórtico norte de la Alhambra de Granada. Por ello para preservar la estructura y cimentación de la muralla nazarí, se decidió separar la nueva construcción, adosándola a la cara exterior del monumento, con una cimentación especial que preserva la originaria nazarí. Jiménez Torrecillas optó por un material diferente, lajas de granito apiladas, trabadas con un milímetro de espesor de un mortero de alta resistencia tan apenas visible, que daba la sensación de material apilado, casi provisional, subrayando de esta manera el carácter permanente e histórico del monumento; sin embargo, se percibe con claridad que se trata de un material diferente, aunque por su color y granulometría armoniza muy bien con el tapial original de la muralla en tono ocre, rojizo y pardo. La intervención tiene un interés añadido ya que, ante la necesidad de solucionar el problema de accesibilidad puesto que debía conciliarse el completamiento de la muralla con el paso a través de ella para poder acceder a una urbanización próxima, el arquitecto diseñó para la parte nueva un doble muro que puede ser atravesado, inspirándose para el interior en los paseos de ronda de la arquitectura militar y en los juegos de luces y sombras que, por ejemplo, aparecen en los baños árabes. El resultado es un espacio sugerente y evocador, inspirado en el mito de la Granada subterránea como manifiesta el propio Jiménez Torrecillas.

Esta restauración, de gran calidad e interés, no ha escapado sin embargo a la polémica ${ }^{85}$, por motivos que van más allá de lo meramente arquitectónico, puesto que fue utilizada por el Ayuntamiento de Granada (cuyo gobierno es detentado por el Partido Popular) que pretendía derribarla ante las protestas suscitadas por los vecinos de la zona, para enfrentarse a la Junta de Andalucía (Partido Socialista), que aprobó el proyecto en su momento puesto que se trata de un Bien de Interés Cultural.

Otros yacimientos como el aparecido bajo el Mercat del Born de Barcelona plantean difíciles retos de cara al futuro ${ }^{86} .9$

En este caso se trata de conciliar la conservación y disfrute de unos restos únicos en toda Europa, unas ruinas del siglo 18 de más de $8.000 \mathrm{~m}^{2}$ de gran valor histórico, con la pervivencia de un magnífico ejemplo de arquitectura 


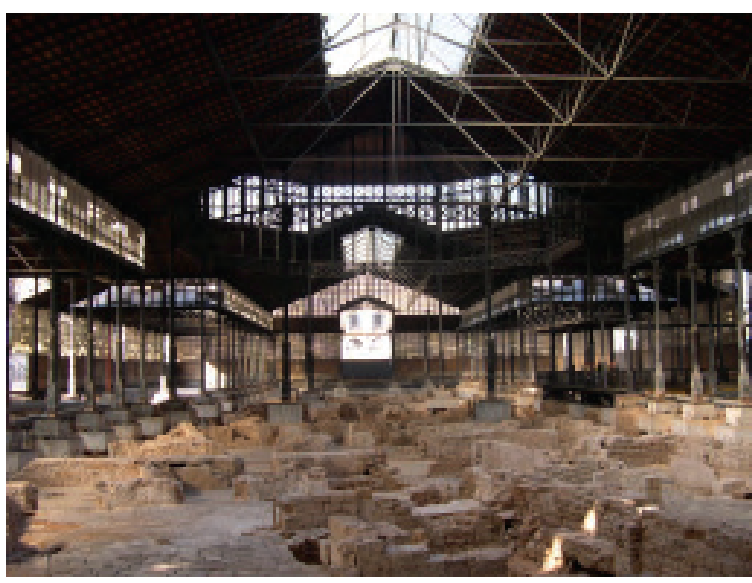

Figura 9: Interior del Mercat del Born Foto: Autora

87 Arquitectura. COAM, n. 319, 1999, p. 107

88 Resolución del 18 de abril de 2006 publicada en Boletín Oficial del Estado, n. 170,18 julio 2006 . industrial del siglo 19: el Mercado (mercat en catalán) del Born, un singular edificio de propiedad municipal diseñado por el arquitecto Josep Fontseré en colaboración con el ingeniero Josep Cornet i Mas (1873-1875), la primera gran construcción barcelonesa en hierro a la vista, clausurado en 1970, que inicialmente iba a ser rehabilitado como biblioteca provincial según proyecto de los arquitectos Enric Sòria y Rafael Cáceres (1997) ${ }^{87}$.

Al iniciarse las obras en febrero de 2002, se descubrieron los restos del barrio de la ribera arrasado por Felipe $\mathrm{V}$ a comienzos del siglo 18, durante la Guerra de Sucesión. Este conflicto bélico, que dividió a las potencias europeas, también tuvo graves consecuencias en nuestro país, puesto que, tras la muerte del monarca Carlos II sin descendencia, una parte del territorio apoyó a Felipe de Anjou (más tarde Felipe V), canditado francés, mientras Inglaterra, Holanda y Austria defendían al archiduque Carlos, un Habsburgo, candidato por el que se decantó Cataluña, temerosa del absolutismo de la corona francesa. Por esta razón Barcelona fue asediada por las tropas de Felipe $\mathrm{V}$ durante trece meses, claudicando la capital catalana el 11 de septiembre de 1714. Derrotada la ciudad, los ingenieros del monarca decidieron construir una ciudadela militar para vigilar el núcleo urbano y prevenir posibles levantamientos, por ello derribaron un millar de construcciones en el barrio de la ribera, dejando una explanada libre donde, cien años después, tras la demolición de las murallas y de la odiada ciudadela (1868), se levantaría el mercado.

Las ruinas hoy descubiertas, que van del siglo 15 al 18, se encuentran en un excelente estado de conservación, ya que el mercado, una estructura muy ligera de hierro y cristal, no había precisado grandes cimientos en su construcción; por otra parte, las casas no se demolieron hasta los cimientos, sino que se cubrieron con tierra para construir una explanada que permitiera la defensa desde la ciudadela militar que se levantó con posterioridad, por lo que han quedado intactos la trama urbana, el pavimento de las calles, los muros de una antigua acequia medieval, muros y plantas de viviendas, escaleras, lavaderos, bodegas, letrinas y hornos. Un hallazgo espectacular, sin duda alguna.

La construcción de la biblioteca inicialmente prevista, precisaba de un auditorio y una planta subterránea para depósito de libros y por tanto suponía la desaparición de este yacimiento de gran valor simbólico-ideológico para los catalanes, ya que sus restos se remontan a la etapa más reivindicada por el nacionalismo catalán, el siglo 18, puesto que servirían de referente material de la mítica resistencia de la ciudad frente a las tropas "centralistas y españolistas" de Felipe V. Todo ello condujo a su declaración como Bien de Interés Cultural en la 
89 EMBT. Enric Miralles/ Benedetta Taglibue. Work in progress. Catálogo de la exposición, Madrid Ministerio de Vivienda, 2005 categoría de zona arqueológica ${ }^{88}$, valorándose, en primer lugar, su importancia para la memoria histórica catalana por su vinculación con hechos trascendentales para la historia de Cataluña y de Barcelona, y en segundo lugar, por tratarse de un ejemplo único en España y en Europa donde se representa una trama urbana de época medieval y moderna de más de $8.000 \mathrm{~m}^{2}$, con una gran variedad de tipologías edilicias bien conservadas, fácilmente legibles y en ejemplar estado de conservación. Obviamente, el paso siguiente fue suspender el proyecto inicial, planteándose en la actualidad la realización de un parque histórico en el que se estudiarán y contemplarán los restos, integrados dentro de un discurso que los conecte con la historia urbana de Barcelona. En la actualidad este parque arqueológico se gestiona desde el Museu d'Historia de la ciutat de Barcelona, estando en fase de ejecución la construcción de una pasarela sobre los restos (proyecto de los arquitectos Enric Sòria y Rafael Cáceres) para permitir el acceso del público.

La conservación de este importantísimo yacimiento arqueológico, al margen de la polémica nacionalista en la que se ha visto envuelto, es una buena noticia y un ejemplo de integración de la arqueología urbana en la vida contemporánea similar a lo realizado con gran éxito, por ejemplo, en Mérida, sobre todo si la comparamos con los muchos restos arqueológicos de época medieval y moderna que han desaparecido en la capital catalana bajo la presión de la especulación inmobiliaria. Estas pérdidas ponen de manifiesto la paradójica situación de una parte importante del patrimonio arquitectónico y arqueológico catalán, y por

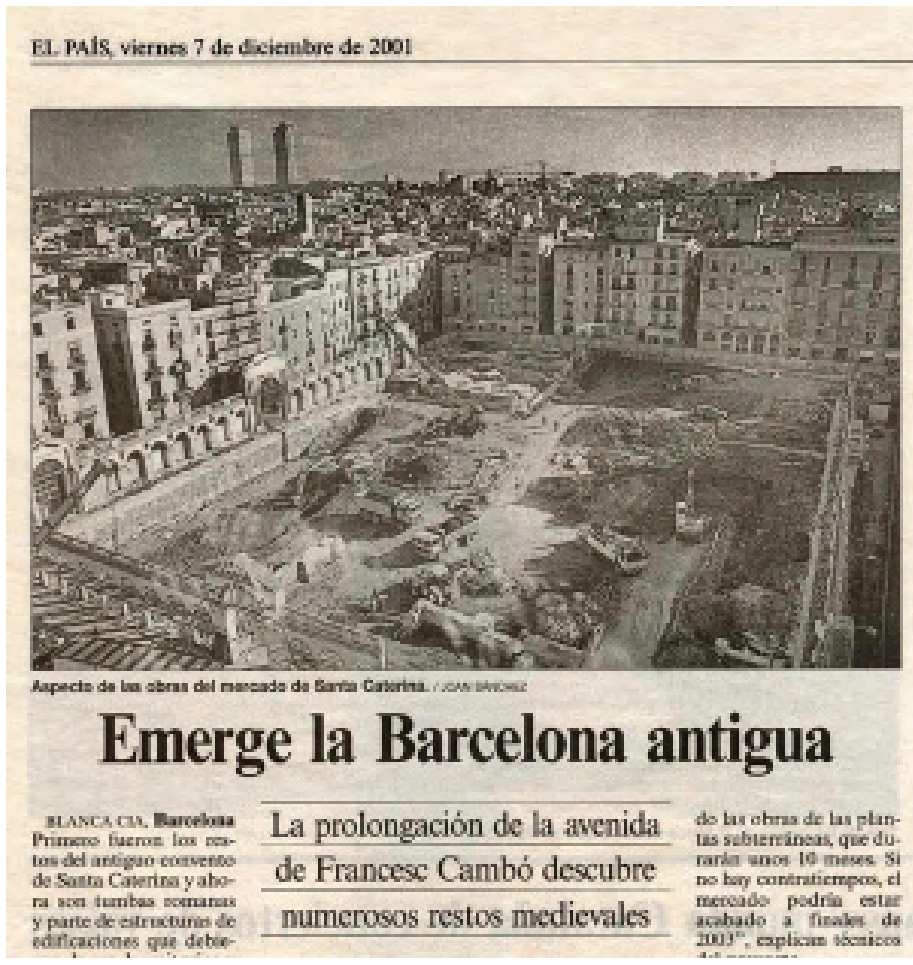

Figura 10: Demolición y vaciamiento del edificio original del Mercat de Santa Caterina y aparición de los restos arqueológicos

Fuente: El País, 7 diciembre de 2001 extensión español, del que sin embargo se ha reconocido su importancia a nivel internacional con la declaración de Patrimonio Mundial para numerosos yacimientos y conjuntos arqueológicos españoles como Mérida, Tarragona o las murallas romanas de Lugo.

En la misma capital catalana hay que analizar la reconstrucción del Mercat de Sta. Caterina (2000-2005), según proyecto de los arquitectos Enric Miralles y Benedetta Taglibue ${ }^{89}$, situado en un solar donde hasta hace pocos años se levantaba el mercado neoclásico, inaugurado en 1848, obra de Francisco Vallés y Josep Mas i Vila, sobre el terreno donde se encontraba el convento de Santa Caterina, construcción medieval del siglo 18 , derribado a su vez en 1835 tras la desamortización de Mendizábal. El mercado se completó avanzado el siglo 19, con la construcción de una ligera cubierta en hierro obra de Joan Torres, conocido como el "Eiffel catalán". En el siglo 20 sufrió transformaciones que lo desfiguraron profundamente y que, en parte, han justificado su derribo.10/11 


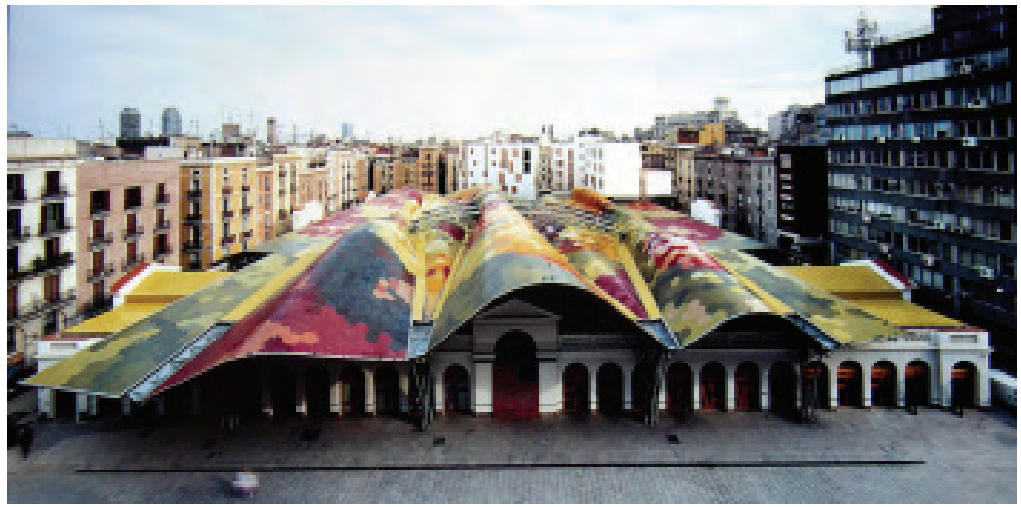

Figura 11: Vista general del nuevo Mercat de Santa Caterina Foto: Revista On Diseño, n. 276, 2006

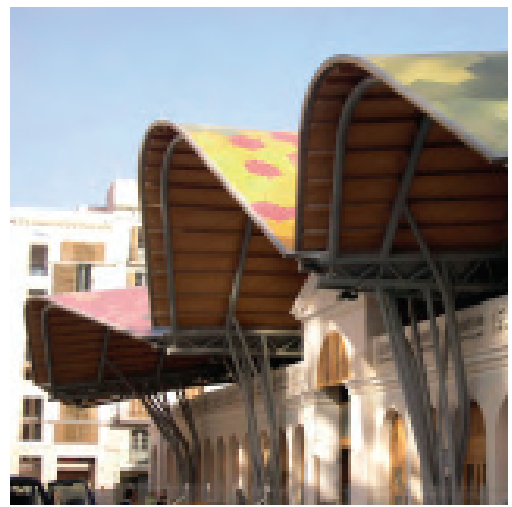

Figura 12: Detalle del voladizo de la cubierta sobre el muro perimetral del mercado original. Estado actual Foto: Autora
90 BUSQUETS, Joan, Barcelona: la construcción urbanística de una ciudad compacta. Barcelona: Ediciones del Serbal, 2004

${ }^{91}$ Agradezco a Rafael Díez Barreñada su amabilidad al facilitarme generosamente el texto inédito de su intervención sobre el antiguo mercado, así como todas las referencias bibliográficas precisas sobre el tema.

92 PÖPPINGHAUS, Hubertus. Participación ciudadana: Qui fa la ciutat? In: HERRERO, Luis F. (Org.). Participación ciudadana para el urbanismo del sig/o $X X I$. Valencia: ICARO, 2005, p. 131-143.
La intervención contemporánea se ha producido tras realizarse un concurso en 1997, ganado por Miralles y Taglibue, y forma parte de un proyecto de rehabilitación urbana más ambicioso que persigue la regeneración de la zona conocida como "Ciutat Vella", con la construcción de viviendas y el "esponjamiento" del barrio a través del derribo de varias manzanas para prolongar la avenida Francesc Cambó. En este contexto, la reconstrucción del Mercat de Santa Caterina es considerada como un factor clave para la recuperación de una zona muy degradada y, como en actuaciones precedentes en la capital catalana, viene acompañada de medidas complementarias que en este caso incluían la construcción de un parking (hay que mencionar que el mercado se encuentra muy próximo a la catedral de Barcelona y al barrio gótico, una de las zonas más visitadas por los turistas $y$, por tanto, necesitada de una infraestructura de este tipo en opinión de las autoridades y por presión de la industria turística) y de un bloque de viviendas sociales y residencia de ancianos dentro del perímetro del antiguo mercado decimonónico.

Lo curioso es que, de entrada, se decidiera el derribo de la construcción neoclásica pre-existente sin pararse a documentar su valor histórico, artístico, urbanístico, cultural en suma. Resulta que, como han puesto en relieve recientes investigaciones ${ }^{90}$, el mercado se insertaba en una trama urbana centenaria, cobrando un gran sentido como elemento clave en la articulación de los recorridos entre la zona portuaria, el llano de Barcelona y el área más alta de la ciudad. Más aún, como ha señalado el arquitecto Rafael Díez Barreñada, en un polémico debate público sobre el barrio y el mercado con Benedetta Taglibue, el responsable municipal y el arquitecto y activista ciudadano Hubertus Pöpinghaus, celebrado en el seno del XXX Curset. Jornadas Internacionales sobre la intervención en el patrimonio arquitetónico (13 diciembre 2007) ${ }^{91}$, el Mercat de Santa Caterina es un ejemplo único de mercado concebido como edificio de tiendas y no como plaza cubierta, siguiendo la tipología inaugurada en París a comienzos del siglo 19, por lo que con su demolición se ha perdido una obra singular del patrimonio catalán y, por ende, nacional. Es, por tanto, un hecho lamentable e irreparable, condenado por colectivos ciudadanos y profesionales que en sus denuncias han puesto en evidencia los actuales procesos de transformación de los centros históricos, dominados por intereses económicos ajenos tanto a la conservación de los tejidos sociales tradicionales como indiferentes (cuando no depredadores) del patrimonio cultural ${ }^{92}$. 
93 FRANCO, Arturo. Venecia nos transforma. In: Blanco y Negro Cultural, suplemento cultural del periódico $A B C, 4$ octubre 2004.

94 CAPEL, Horacio. El debate sobre la construcción de la ciudad y el llamado "Modelo Barcelona", Scripta Nova, Revista Electrónica de Geografía y Ciencias Sociales, Universidad de Barcelona, n. 233, p. 1-69, 15 de febrero de 2007

95 PIZZA, Antonio. Barcellona "critica". Gli scenari dell'attualità, Area. Rivista internazionale di architettura e arti del progetto, Milano, n. 6 p. 4-13, gennaio-febbraio 2007, número monográfico "Critical Barcellona".
Iniciadas las obras, aparecieron, como era de esperar, numerosos restos arqueológicos no sólo del gran convento dominico construido en el siglo 18, sino también un primer edificio conventual levantado entre los siglos 11 y 12, una necrópolis cristiana del siglo 4. d.C., una villa romana e incluso huellas de poblamiento que se remontan a la edad del Bronce Inicial (hacia el 1.800-1.500 a.C.). Todos estos datos, obtenidos después de las pertinentes excavaciones y estudios arqueológicas, evidencian que se trata de una zona muy importante en la historia de la ciudad. Sin embargo, este hecho no fue suficiente para merecer su conservación, por lo que, una vez analizados, la mayor parte del yacimiento fue destruido para facilitar la construcción del parking. A la destrucción del mercado neoclásico se añadía, de este modo, la salvaje eliminación de unos valiosos restos históricos. En el dilema entre arqueología e historia y desarrollo, se hacía prevalecer, de nuevo, la renovación a toda costa.

Un tercer elemento pesó, seguramente, en la toma de decisiones por parte del Ayuntamiento: la necesidad de conseguir un nuevo "icono arquitectónico" a añadir a la lista de edificios sobresalientes de la capital catalana usados como reclamo turístico. De hecho el nuevo mercado de Miralles y Taglibue es presentado, en los mismos folletos informativos redactados por el Ayuntamiento, como "uno de los ejemplos más exitosos de arquitectura contemporánea en Barcelona", una circunstancia que viene refrendada a nivel internacional por la difusión y premios que ha obtenido este edificio que fue seleccionado en la IX Bienal de Venecia (septiembre 2004) dirigida por Kurt Foster, en el apartado denominado Topografías junto con edificios tan diferentes como el Museo Paul Klee de Berna de Renzo Piano y la Ciudad de la Cultura en Santiago de Compostela de Peter Eisenman ${ }^{93}$.

Construido el nuevo mercado, del original del siglo 19 sólo queda el muro perimetral al que se le ha superpuesto una potentísima estructura metálica protegida por una cubierta ondulada de madera y teja cerámica de impactante diseño y color; a su vez, de los $7.000 \mathrm{~m}^{2}$ de restos arqueológicos se conservan tan sólo 700, mostrados parcialmente en un centro de interpretación que se integra en la nueva construcción. En este caso concreto la valoración resulta difícil, ya que si desde el punto de vista de la arquitectura de nueva creación esta obra destaca por su potencia plástica y visual y su originalidad, enmarcándose en esa tendencia de la arquitectura contemporánea que fomenta la espectacularidad y el contraste con el entorno, si nos atenemos a la relación con la arquitectura preexistente y el valor histórico del lugar, no podemos más que concluir que la nueva cubierta reduce hasta el ridículo al único resto que se ha dejado de la construcción original (el muro perimetral), por lo que caben varias preguntas, entre ellas porqué se ha conservado este muro del mercado original que en apariencia tenía escaso valor arquitectónico. Y si por el contrario la construcción tenía interés como parece por los datos hasta ahora aportados ¿por qué no se ha conservado completa? ¿Por qué, además, se ha decidido la eliminación sin escrúpulos de los restos arqueológicos?

No somos los únicos en plantear estas dudas. Horacio Capel, catedrático de Geografía Humana de la Universidad de Barcelona, calificaba de "innecesaria la estructura realizada por el arquitecto Enric Miralles para la remodelación del mercado neoclásico de Santa Caterina", añadiendo que

La actitud individualista de algunos arquitectos, que se consideran creadores de obras singulares y que no tienen en cuenta el ambiente en 
96 LAHUERTA, Juan José. Destrucción de Barcelona. Barcelona: Mudito habla, 2005, p. 15.

97 LAHUERTA, op. cit., p.16. que se levantan, ha tenido consecuencias nefastas. Ha llevado a edificios que contrastan de forma hiriente con el paisaje circundante, que no respetan los ritmos compositivos de la edificación existente, la arquitectura unitaria de los edificios de épocas distintas y estilos diversos. ${ }^{94}$

La ciudad actual, en opinión de Capel, es modelada por el capital y organizada para el consumo, y en este sentido debe enmarcarse actuaciones como la realizada en el Mercat de Santa Caterina, en las que se sacrifican los valores patrimoniales a favor de una arquitectura espectacular que refuerza una imagen determinada de Barcelona, lista para ser consumida por los turistas. Esta situación conduce a la capital catalana al borde del parque temático, banalizando y devaluando un patrimonio arquitectónico histórico, variado y extenso como ha denunciado el arquitecto Antonio Pizza ${ }^{95}$, profesor de la Escuela Técnica Superior de Arquitectura de Barcelona. Pizza critica, sin aludir expresamente al mercado de santa Caterina (aunque entendemos que se refiere al mismo), que se hayan realizado numerosas sustituciones y reconstrucciones sin haberse planteado tan siquiera la alternativa de una recuperación, aunque fuera parcial. Más poético, aunque igualmente duro con este tipo de intervenciones, resulta el discurso de Juan José Lahuerta, como Pizza arquitecto y profesor de la ETSAB, quien ha llegado a escribir un melancólico y evocador texto (Destrucción de Barcelona), en el que describe "la destrucción planificada y comercializada de la ciudad, y la ruina y desaparición de la vida que habita en ella"96, reflexionando al respecto:

¿qué puede haber de más cruel, de más feroz, que aspirar toda la carne de un barrio conservando sus huesos o caparazones, y de más desvergonzado que usarlos como signo de supuesto respeto, de recuerdo o de memoria? Memoria: ¿de qué o de quién? Los lugares en los que esas fachadas, convertidas en muros solitarios, en imagen terrible del vacío más despótico, de la desaparición total, se contraponen directamente a las nuevas construcciones, no pueden resultar más elocuentes, no sólo por la ínfima mala calidad de la arquitectura recién construida, sino, sobre todo, por la oposición entre esos muros marcados y heridos por el tiempo, y esos otros lisos y nuevos que proclaman nuestra absurda pobreza. ${ }^{97}$

En este caso, como en muchos otros contemporáneos en España y en Europa, nos encontramos con la dificultad de analizar crítica y unilateralmente intervenciones que pueden ser valoradas desde diferentes puntos de vista, en las que una obra de nuevo diseño sobre un solar histórico trabaja por contraste imponiéndose a la arquitectura y al espacio histórico a través de la espectacularidad de sus formas, planteándonos qué conexión queda en ellas con la memoria del lugar o el valor histórico y arquitectónico de la preexistencia, bien sea un monumento o una ruina arqueológica. Existe, además, la paradoja de que en muchos casos estos nuevos elementos o construcciones se presentan como indispensables si se quiere garantizar una correcta funcionalidad de los edificios, sobre todo cuando se adapta la arquitectura histórica para usos contemporáneos como en los numerosos casos de transformación de monumentos en museos y centros culturales realizados en la misma Barcelona, pero en realidad tras esta defensa de la inserción de nueva arquitectura a toda costa se esconde en muchos casos el deseo de producir una nueva imagen, más impactante del monumento, en consonancia con la tendencia a la grandilocuencia y la espectacularidad a toda costa evidente en la cultura arquitectónica del presente. Es la "fiebre de los 


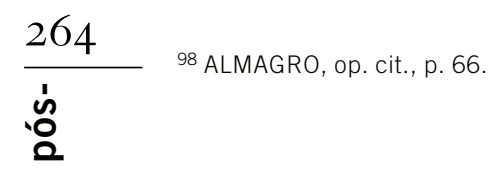

edificios icono" que ha afectado también al mundo del patrimonio arquitectónico y de la que no se escapa la metrópoli catalana (recuerdese que ya tiene un nuevo edificio-estrella: la Torre Agbar de Jean Nouvel).

Para concluir, queremos recuperar por su vigencia y actualidad la opinión expresada hace quince años por el arquitecto Antonio Almagro sobre la intervención de Grassi y Portaceli en el teatro romano de Sagunto, como colofón a esta reflexión crítica acerca de la relación entre arquitectura contemporánea y restos históricos, suscitada a raíz de la actuación de Miralles y Taglibue sobre el Mercat de Santa Caterina, que evidencian dos maneras completamente distintas de intervenir sobre los restos arqueológicos que ya hemos contrastado en los casos analizados en este artículo.

La conservación del patrimonio no se presta al desarrollo de acciones eminentemente creativas, sin que por ello deban descartarse. Pero parece evidente que en la acción conservadora deben primar los valores del bien a conservar sobre los que nuestra actividad pueda aportar. Resultan por ello extrañas y muy poco defendibles actitudes, y más aún acciones, que justifican a ultranza la aportación de creaciones arquitectónicas actuales sobre nuestros monumentos, amparadas dentro de lo que deberían ser acciones de conservación, y máxime cuando se financian con fondos destinados a este último fin. ${ }^{98}$

\section{Ascensión Hernández Martínez}

É professora do Departamento de História da Arte da Faculdade de Filosofia e Letras da Universidade de Zaragoza, desde 2000. Fez seu doutorado em História da Arte, especializando-se em temas de arquitetura contemporânea e teoria e história da restauração de bens culturais. Suas principais linhas de pesquisa atualmente são: teoria e história da restauração de monumentos na Espanha no século 20, com especial atenção nas intervenções realizadas em Aragão sob o primeiro franquismo; a reutilização de espaços industriais para usos artísticos e culturais, com ênfase nos novos espaços de criação e exibição, as relações entre criação artística e restauração, o museu como tipologia arquitetônica e produto cultural; por fim, teoria e crítica da arquitetura atual. A professora tem várias publicações na área, entre elas, o livro La clonación arquitectónica (Madri: Siruela, 1997; traduzido para o italiano: Milão: Jaca Book, 2010). 